\title{
A Brief Review about Salinity Gradient Energy
}

\author{
Yunus Emami ${ }^{\mathrm{a}}$, Sajjad Mehrangiz ${ }^{\mathrm{a}}$, Ahmad Etemadi ${ }^{\mathrm{b}}$, \\ Asgar Mostafazadeh $^{c}$, Saeid Darvishi ${ }^{\mathrm{a}}$ \\ ${ }^{a}$ Mechanical Engineering Department, Urmia University of Technology, Urmia, Iran \\ ${ }^{b}$ Chemical Engineering Department, Urmia University of Technology, Urmia, Iran \\ ${ }^{c}$ Electrical Engineering Department, Urmia University of Technology, Urmia, Iran
}

\begin{abstract}
Increasing the greenhouse gases concentration, climate change and the global concerns about the fossil fuels pollutants lead scientists and researcher toward the energy production by the renewable energy sources. Replaced the energy generation sources from the fossil fuels to the renewable energy sources is one of the important project that scientists and researchers has been worked and the good potentials of this sources of energy make them to most studies and researchers from this important. Salinity gradient energy or blue energy is an of the high potential energy sources that placed in renewable energy's list. The salinity gradient energy can be one of the important sources of the renewable energy to electricity generation for global electrical demand in future. When saline and fresh water mixes the Gibbs free energy is released. This energy could be used for generation of electrical power by some methods. There are two promising techniques for the generation energy from salinity gradient including RED and PRO methods. According the estimates of power available in the world salinity gradients energy are estimated between 1.4 and $2.6 \mathrm{TW}$, this amount of power generation in comparison to other marine renewable energy sources is a good potential. This paper is over review for salinity gradient energy, RED and PRO methods.
\end{abstract}

Keywords: Renewable energy, salinity gradient energy, electrodialysis (RED), Pressure Retarded Osmosis (PRO)

\section{Introduction}

By increasing the power demands in the world and global concerns about the greenhouse gases that released from burning the fossil fuels, the requirement to clean sources of energy and their conversion technologies is obvious. The increasing of $\mathrm{CO}_{2}$ concentration in the earth atmosphere as an of the greenhouse gas make the many researches to developed the renewable energies technology. Fig. 1 shows the relation between the global temperature growth and increasing the $\mathrm{CO}_{2}$ in the atmosphere of earth.

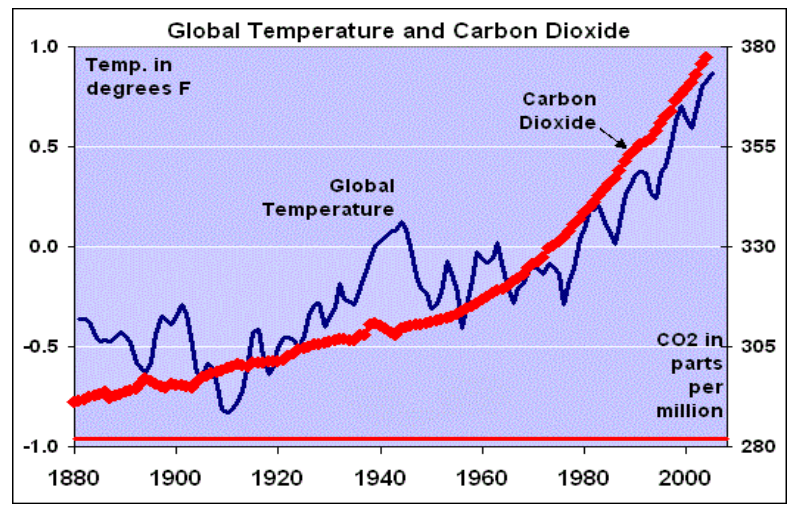

Fig. 1. Growth of the global temperature versus increasing the $\mathrm{CO}_{2}$ concentration

\footnotetext{
* Manuscript received July 10, 2012; revised August 10, 2012.

Corresponding author. Tel.: +98-44135541180-1; fax: +98-4413554184; E-mail address: ahmadetemadi112@gmail.com.
} 
So the importance of the renewable energy as the clear, cheap and salubrious with environmental is clearly obvious. The renewable energy sources are being derived from ocean include: tidal power, wave power, ocean thermal energy conversion, ocean currents, ocean winds and salinity gradients. The tidal power, wave power and ocean thermal energy conversion has been well-developed. By using the conventional technology we can convert the kinetic energy to electricity. To harnessing the kinetic energy in waves and wind we need to present different techniques. Ocean thermal energy conversion is the extracting energy with using a heat engine. These sources of energy may exist in sites with large temperature differences. The salinity gradient energy is achievable in places that a solution flow with a specific salinity concentration runs into other solution with different salinity concentration. The best application of this source of energy when the low salinity flows of water (river water) mixing with saline water (see water) so the main factor in salinity gradient energy is the "difference of chemical potential" between the diluted and concentrated solutions. There are one estimate that shows the total discharge of global rivers is $1.3 \times 10^{6} \mathrm{~m}^{3} / \mathrm{s}$ [1], Therefore the global potential of salinity gradient of power is $2.8 \mathrm{TW}$ this amount is near to 2.6 TW that estimated in 1977 by Wick and Schmitt [2]. According to studies [3] in 2008 about the average world energy consumption, this amount of energy is more than the global electricity consumption [4]. In comparison to other sources of marine energy the salinity gradient energy are in the same order as wave energy or thermal gradients and are 100 times higher than those of tidal energy [5]. Replacing coal-fired power plants with salinity gradient energy power plants could reduce global greenhouse gas by $10 \mathrm{Pg} \mathrm{CO}_{2}$-eq/year $\left(\sim 10^{10}\right.$ tons /year), when calculated with standard emission factors [5]. This number indicated the importance of this source of energy. There are different techniques for extracting energy when the river water and seawater mix. The techniques described are, pressure retarded osmosis (PRO) [6,7], reverse electrodialysis (RED) [8-10], vapor pressure difference utilization [11], the so called ' hydrocratic generators' [12], mechanochemical methods [13], membraneless hydro-voltaic cells [14] and cryoscopic techniques such as freezing temperature difference utilization [15]. In this study we try to explain the salinity gradient energy source and the RED and PRO as two promising techniques for the generation energy from this source of energy.

\section{Salinity Gradient of Energy}

The salinity gradient energy is already known for a long time for example it is mentioned the first studies [16] in 1953. Pattle [16] indicates "When a volume V of a pure solvent mixes irreversibly with a much larger volume of a solution the osmotic pressure of which is $\mathrm{P}$, the free energy lost is equal to PV. The osmotic pressure of seawater is about 20 atmospheres, so that when a river mixes with the sea, free energy equal to that obtainable from a waterfall $680 \mathrm{ft}$. (about $200 \mathrm{~m}$ ) high is lost. There exists an untapped source of power which has been unmentioned in the literature. The two membrane-based techniques that can be used for converting the salinity gradient energy to sustainable electricity [17] is pressure-retarded osmosis and reverse electrodialysis. The amount of this electricity is predicted by some studies. By concerning reverse electrodialysis, Forgacs [18] conservatively predicted a net energy yield of $0.35 \mathrm{MJ}$ per $\mathrm{m} 3$ of river water. Audinos [19] calculated an energy recovery of $21 \%$ (i.e., without taking into account parasitic system losses for pumping and DC/AC conversion). The experimental studies of Jagur-Grodzinski and Kramer [20] shows that the obtained amount of energy (net) could be 0.25-0.6 MJ per $\mathrm{m} 3$ of river water that it is deponds on the chosen power density. There are some studies that presented the equations to calculated the amount of power output from RED and PRO methods such as: Murphy [21], Lacey [22,23],Weinstein and Leitz [24], Forgas [25], Emren and Bergstrom [26]. The first technique uses in effect the osmotic pressure difference by implementing reverse osmosis membranes $[27,28]$

\subsection{Pressure Retarded Osmosis (PRO)}

There is clarity showed the principle of osmotic pressure in Fig. 2. In the top part of Fig. 2 the thermodynamic effect of mixing two different solutions are indicated. At the first time (upper left section) 
both liquids are separated by water tight panel. The system evolves spontaneously into a prefect mixture when removing this physical barrier (upper right). To reaching the maximum entropy value of the system the ions of salt tend to disperse homogeneously over the total volume of solution. In the next time if the panel would be replaced by a semi- permeable membrane which only allows the water molecules to pass (see lower lift section of Fig. 2), due to tend system to obtain the equilibrium situation and also tend to evolve towards a perfect mixture there is no thermodynamic difference between the upper left and lower left starting position. As a result of the diffusion water molecules from dilute solution (A) into concentration solution (B), the total volume of the B will increase and the level rises until a specific pressure head is reached which counteracts the diffusion of the water molecules from A into $\mathrm{B}$. The equilibrium pressure head is called osmotic pressure of the solution B. According to experiments the equivalent pressure head between 0.5 molar seawater and fresh water (river water) is about 24 atm [29]. This pressure is equivalent to a $240 \mathrm{~m}$ water head [30]. So this effect are very powerful and make a strong permeate flow which able to drive hydraulic turbines and electrical generators to produce electricity from the osmotic effect. In nature, the massive transport of water through tree trunks up which can be tens of meters high is also based on osmosis [31]. When applying pressure of the concentration solution onto salt water larger than its osmotic pressure it is possible to reverse the process in a way that the water molecules are forced to diffuse through the semi-permeable membrane into dilute solution. This is called reverse osmosis and the main principle of the producing potable water from seawater [32]. In the PRO process, water with no or low salt gradient is fed into the plant and filtered before entering the membrane modules. The illustration in Fig. 3 shows salty water pumped from the sea and filtered before it is pressurized and fed into the membrane module [33].

Study shows that the power production from $3,000,000 \mathrm{~m}^{3} / \mathrm{d}$ ("moderate" flow rate) of river water by interaction with seawater in presure-retared osmosis (PRO) is 22,300 KW [28]. According to Lee et al [34] this potential power couldn't be produced economically by PRO. The cost data on the PRO plants were largely based on those of the RO plant in Yuma, Arizona [35]. At the Yuma plant the specific cost was 1000 dollars per daily cubic meter of permeate.

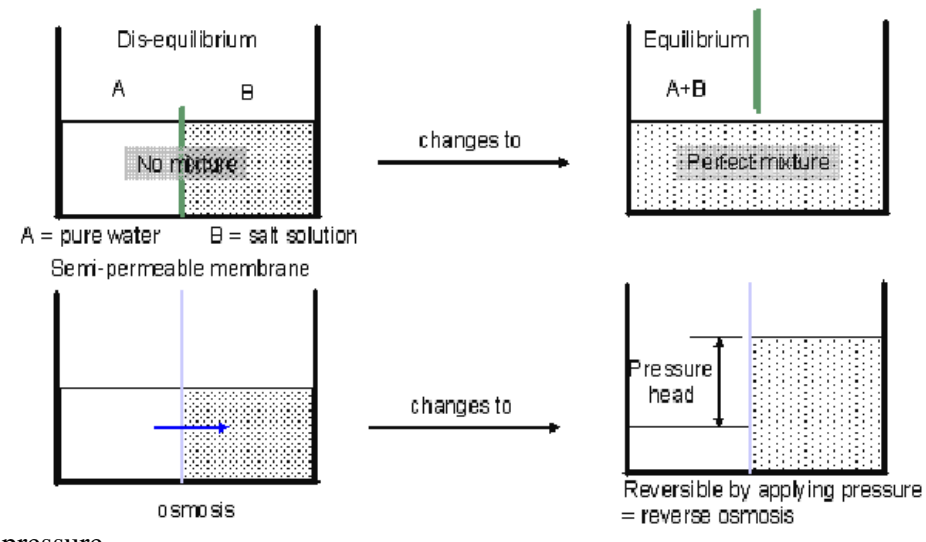

Fig. 2. Principle of osmotic pressure.

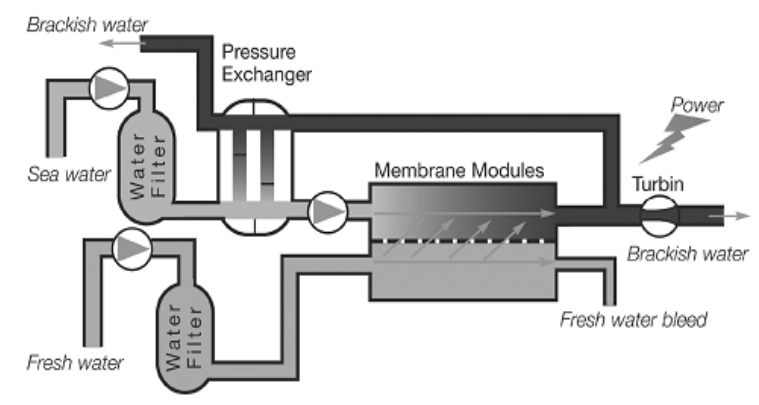

The osmotic

power process

Fig. 3. A simplified PRO process diagram 
The osmotic pressure is increased by increasing the concentration of B solution and due to it allow to increasing the amount of available energy.

\subsection{Reversed Electrodialysis RED}

A second technique uses the dialysis concept and mostly named reversed electrodialysis. In electrodialysis (ED) two compartment of dilute and concentration solution are separated in an alternating way by cation and anion-conductive membranes (CM and AM). With considering the result of the electric field, anions move to the anode (+) and cations to the cathode (-). From the alternating series of CM and $\mathrm{AM}$, cations and anions are concentrated in the concentrate chambers while the diluation chambers are diluted or be desalinated. So ED is the technique to convert a salt solution into two fractions: a concentrate and a dilute. The basics of ED can be found in e.g. [35]. This process can be reversed in a way that a voltage is created across the electrodes [31]. This voltage can be used to an electrical device to drive such device with salinity gradient power based electrical energy. This technique of the harnessing energy from two different concentration of salt is called salinity gradient power by rivers electrodialysis. There are important contributions to the basics understanding the electric energy generation by RE method in [36,37]. The principle is shown very obviously in Fig. 4, showing 8 cell pairs arbitrarely. For first time Lacey presents some pragmatic calculations based on a theoretical model of a cell pair within a RE set-up and some model parameter values as obtained from experimental considerations. The Fig. 5 is indicated the relationship between the current density and power generation by rivers electrodialysis per cell pair according Lacey. This study about the indicating value is related (corresponded) to cell pair model of Lacey and no high integration is done, that is essential for a real RE stack and also are to be considered as estimates. The assumed conditions in those calculations by Lacey were: concentrate compartment thickness $1 \mathrm{~mm}$, dilute compartment thickness $0.5 \mathrm{~mm}$, concentrate at $4 \mathrm{~N}$, dilute at $0.1 \mathrm{~N}$, membrane resistances of $10-4 \mathrm{Ohm} . \mathrm{m}^{2}$ and temperature at $298 \mathrm{~K}$.

Studies [38] show that based on power density, PRO has a better potential for harvesting salinity gradient energy and also for commercially available membranes with potential possible improvements to the membranes this amount of difference becomes greater. In all of this the context of a full-scale module-scale process design must be considered.

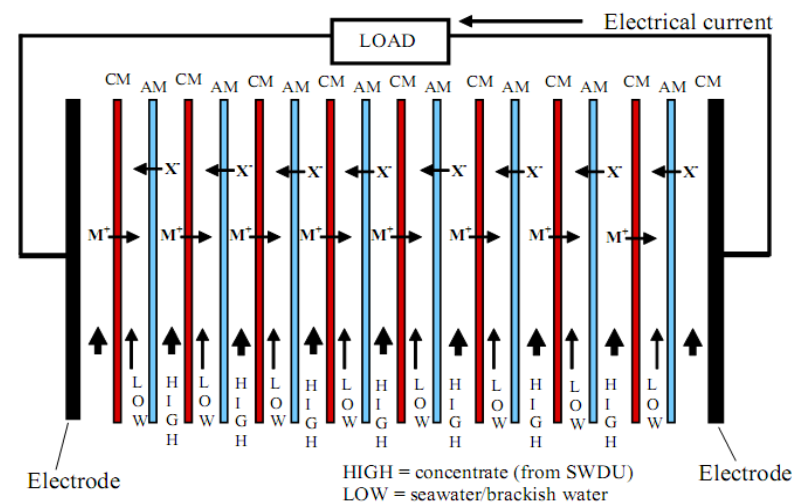

Fig. 4. 'Battery' principle of SGP-RE [31]

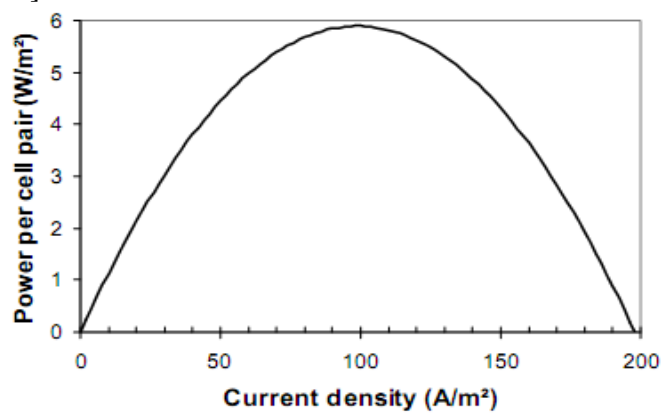

Fig. 5. SGP-RE generated by one cell pair according to Lacey [31] 


\section{Conclusion}

The salinity gradient energy is a most promising energy source for generation electricity with the high potential available in comparison to anther sources of renewable energy. There are many places in the world which the salinity gradient energy is available, so installation the plants in rivers mouth can be produced and supported the huge amount of global electricity demands in future. For increasing the technical potential of salinity gradient energy the plant is constructed in the river moth, because of decreasing the energy losses for pumping or transferring. This paper presented the over review for salinity gradient energy and discussed about the important techniques (i.e. RED and PRO) for harnessing energy from this type of renewable energy source.

\section{References}

[1] Kuleszo JT. The global and regional potential of salinity-gradient power. Dept. Environmental Sciences, Environmental Systems Analysis Group. Wageningen University and Research centre; 2008.

[2] Wick GL, Schmitt WR. Prospects for renewable energy from sea. Mar. Technol. Soc. J., 1997; 11:16-21.

[3] Energy Information Administration. [Online]. Avalable: http://www.eia.doe.gov

[4] Veerman J, Saakes M, Metz SJ, Harmsen GJ. Reverse electrodialysis: a validated process model for design and optimization. Chemical Engineering Journal, 2011; 166(1):256-268

[5] Post JW. Thesis, Blue Energy: electricity production from salinity gradients by reverse electrodialysis. Wageningen University, Wageningen, NL; 2009.

[6] Loeb S. Osmotic power plants. Science, 1975; 189:654-655.

[7] Loeb S. Production of energy from concentrated brines by pressure retarded osmosis. 1. Preliminary technical and economic correlations. J. Membr. Sci., 1976; 1:49-63.

[8] Pattle RE. Electricity from fresh and salt water-without fuel. Chem. Proc. Eng., 1955; 35:351-354.

[9] Pattle RE. Improvements to electric batteries. Patent GB 731729 (1955).

[10] Pattle RE. Production of electric power by mixing fresh and salt water in the hydroelectric pile. Nature, 1954; $174: 660$.

[11] Olsson M, Wick GL, Isaacs JD. Salinity gradient power-utilizing vapor-pressure differences. Science, 1979; 206:452-454.

[12] Finley W, Pscheidt E. Hydrocratic generator. US Patent 6,313,545 B1 (2001).

[13] Sussman MW, Katchalsky A, Mechanochemical turbine: a new power cycle. Science, 1970; 167:45-47.

[14] Lagger G, Jensen H, Josserand J, Girault HH. Hydro-voltaic cells. Part 1. Concentration cells. J. Electroanal. Chem., 2003; 5445:1-6.

[15] Kniajev V. Energy of salinity gradient-new source of energy with minimal environmental impact. In: Abstracts from the International Workshop "Result of Fundamental Research for Investments” (IWRFRI'2001'), 2001.

[16] Pattle RE. Production of electric power by mixing fresh and salt water in the hydroelectric pile. Nature, 1954; $174: 660$.

[17] Post JW, Veerman J ,Hamelers HVM, Euverink GJW, Metz SJ, Nymeijer DC, Buisman CJN. Salinity-gradient power: Evaluation of pressure-retarded osmosis and reverse electrodialysis. J of Membr. Sci., 2007; 288(1-2): 218-230.

[18] Forgacs C. Recent developments in the utilization of salinity power. Desalination, 1982; 40:191-195.

[19] Audinos R. Electric-power produced from 2 solutions of unequal salinity by reverse electrodialysis. Indian J. Chem., Sect. A: Inorg. Bio-Inorg., Phys., Theor., Anal. Chem., 1992; 31:348-354.

[20] Jagur-Grodzinski J, Kramer J, Novel R. Process for direct conversion of free-energy of mixing into electric-power. Ind. Eng. Chem. Process Des. Dev., 1986, 25(2):443-449.

[21] Murphy GW. Office of saline research and development report 4. U.S. Government Printing Office, Washington, DC (1956).

[22] Lacey RE. Symposium on saline water conversion. National Academy of Sciences/National Research Council Publication, Washington, DC; 1958.

[23] Lacey R.E. Dechema-Monagr. 47, 673 (1962)

[24] Weinstein I, Leitz F. Electric power from differences insalinity: the dialytic battery. Science, 1976, 191:557.

[25] Forgacs C. Generation of electricity by reverse electrodialysis (RED). Ben-Gurion University of the Negev, Israel; 1975.

[26] Emren A, Bergstrom S. Miami lnt. Conf. on Alternative Energy Sources, 1977:887.

[27] Loeb S. Energy production at the Dead Sea by pressure- retarded osmosis: challenge or chimera. Desalination, 1998 ; 120 (3):247-262

[28] Loeb S. Large-scale power production by pressure-retarded osmosis, using river water and sea water passing through spiral modules. Desalination, 2002; 143(2):115-122.

[29] Bromley L, Singh S, Ray P, Srivhar S, Read S. Am. Inst. Chem. Engng J., 1971; 20:326. 
[30] Wick GL. Power from salinity gradients. Institute of Marine Resources. Scripps Institution of Oceanography. University of California.

[31] Brauns E. Towards a worldwide sustainable and simultaneous large-scale production of renewable energy and potable water through salinity gradient power by combining reversed electrodialysis and solar power. Desalination, 2008; 219(1-3):312-323.

[32] Amjad Z. Reverse osmosis membrane technology. In: Water Chemistry and Industrial Applications. New York: Van Nostrand Reinhold, 1993.

[33] Skilhagen SE, Dugstad JE, Aaberg RJ. Pressure difference between waters with varying salt gradients Osmotic power power production based on the osmotic. Desalination, 2008; 220:476-482.

[34] Lee KL, Baker R, Lonsdale H. Membranes for power generation by pressure-retarded osmosis. J. of Membr. Sci., 1981; 8:141-171.

[35] Wilson JR. Demineralization by Electrodialysis. Glasgow: Butterworths Scientific Publications London, The University Press, 1960.

[36] Weinstein JN, Leitz FB. Electric power from differences in salinity: the dialytic battery. Science, 1976; 191:557.

[37] Lacey RE. Energy by reverse electrodialysis. Ocean Eng., 1980; 7:1-47.

[38] Ramon GZ, Feinberg BJ, Hoek EMV. Membrane-based production of salinity-gradient power. Energy \& Environmental Science, 2011; 4(11):4423-4434. 